\title{
Atom Search Optimization Algorithm for Allocating Distributed Generators in Radial Distribution Systems
}

\author{
Ikrom Khonturaev, Mansur Khasanov", Muhiddin Anarbaev, Abror Kurbanov, Anvar \\ Suyarov and Urinboy Jalilov \\ Jizzakh Polytechnic Institute, Jizzakh, Uzbekistan
}

\begin{abstract}
In recent years the use of renewable energy sources (RES) by many power grid companies worldwide has increased significantly. The trend towards RES use is mainly due to environmental issues and rising fuel prices associated with conventional electricity generation. This paper introduces a hybrid approach to find the optimal location and size of distributed generations (DG) in the radial distribution system (RDS). The proposed approach is based on the atom search optimization (ASO) technique to calculate the optimal allocation of DGs and power loss sensitivity (PLS) index to obtain the best buses for DGs installation in RDS. The presented approach is applied to IEEE 33-bus RDS to increase voltage profile and minimize the power losses. The results obtained prove that the developed approach can be highly effective in integrating DG into RDS compared to many other methods in the literature.
\end{abstract}

\section{Introduction}

The use of RES is growing significantly in many countries around the world. Government support and policy are the most important impetus for developing the RES industry [1-2]. However, the unpredictability and variability of RES is a major obstacle to its development, causing several problems for power systems. Reliability, stability analysis, power system safety, and frequency regulation are key technical issues that affect when RES is integrated into power systems [3-4].

Integration of the RES-based DGs into RDS is a major challenge. Because the characteristics of DGs are different from conventional power generators, different methods need to be used to model them and evaluate their overall contributions. In recent years, several metaheuristic and analytical approaches have been developed to study the allocation of DGs and calculate their advantages [5-8].

To find the optimal location and size of the DG to minimize the power loss in the RDS by using the genetic algorithm (GA) has been proposed in [5]. In [6], the hybrid optimization technique of the gray wolf has been presented for finding the optimal location and size of the DG to minimizing power losses in RDSs. In [7], the backtracking search optimizer algorithm (BSOA) has been presented to identify the optimal location and size of

*Corresponding author: hasanov6654525@mail.ru 
multiple type of DGs to minimize the loss of active power. In [8] developed an evolutionary algorithm (EA) to find the optimal location and size of the DG to minimize the power loss.

The allocation of the DG units must take into account several factors during the planning stage: using the best technology, the DG units' number, the size and location of DG units, and the connection type [9]. In this paper, we will study two RES-based DG technologies: the wind turbine (WT) and photovoltaic (PV) units considering the number and size of units and whether these units are generating only active power or active and reactive power. The main goal is to minimization power loss and, at the same time, satisfy system constraints within a specific limit. The optimization problem is solved by the combination of the power loss sensitivity (PLS) index and the Atom search optimization algorithm (ASO) [10]. The optimization technique is performed, taking into account the allocation of one and several DG units. Finally, this developed approach has been examined on the IEEE 33-bus RDS to test its effectiveness.

The remaining of this paper is arranged as follows: describe the methodology adopted in work in Section 2. Section 3, the obtained results are discussed. In Section 4, the main conclusions of the paper are presented.

\section{Materials and Methods}

\subsection{The proposed methodology of optimal DGs allocation}

Minimizing power losses taken into consideration as the main goal of this paper, which is obtained by determining the optimal location and size of the DGs in the RDS.

\subsubsection{Load flow analysis}

Load flow analysis is important in an allocation problem since constraints, such as bus voltage constraints, are involved in the optimization problem to power loss minimization. The backward and forward load flow algorithm (LFA) uses the radial nature of the RDS, and it is more effective than traditional LFA for radial systems [11, 12]. Therefore, in this paper, the backward and forward LFA has been changed under the analysis of the load flow of RDS (incorporate DG).

\subsubsection{PLS index}

The appropriate buses for the integrating of the DGs are definite by using the PLS index. The PLS index is widely used to solve DG sizing and locating problems in RDS [13]. Equivalent schemes of RDS are illustrated in Figure 1.

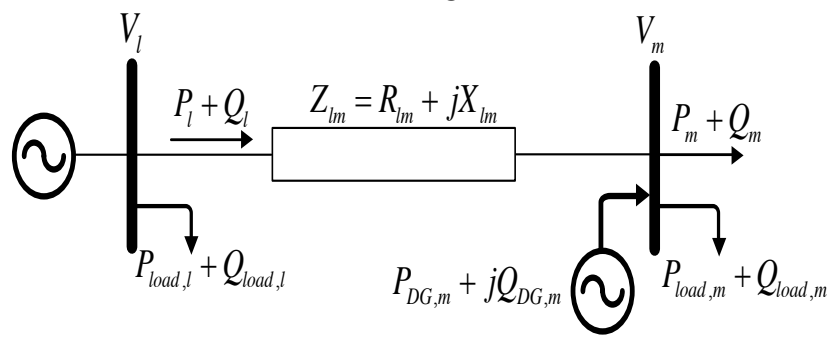

Fig. 1. Equivalent schemes of RDS 
Where, $P_{l}$ and $P_{m}$ are active powers of buses $l$ and $m$, respectively. $Q_{l}$ and $Q_{m}$ are reactive powers of buses $l$ and $m$, respectively. ${ }^{V_{l}}$ and $V_{m}$ are voltages of buses $l$ and $m$, respectively. $R_{l m}$ and $X_{l m}$ are active and reactive resistances between bus $l$ and $m$. $P_{D G, m}+j Q_{D G, m}$ are active and reactive powers of DG unit at bus $m . \quad P_{\text {load }, l}+j Q_{\text {load }, l}$ and $P_{\text {load }, m}+j Q_{\text {load }, m}$ are active and reactive load demand of buses $l$ and $m$, respectively.

The active power loss between $l$ and $m$ buses can be expressed as follows [13-15]:

$$
P_{l o s s}=\frac{\left(P_{m}^{2}+Q_{m}^{2}\right) \cdot R_{l m}}{\left(V_{m}\right)^{2}}
$$

where, $P_{l o s s}$ is active power loss.

PLS index can be expressed as:

$$
\frac{\partial P_{l o s s}}{\partial Q_{m}}=\frac{2 Q_{m} \cdot R_{l m}}{\left(V_{m}\right)^{2}}
$$

After determined the PLS index for all buses organized in descending order. The order determines the priority of buses for DG installing. The calculated PLS index values are illustrated in Figure 2.

\subsection{Problem formulation}

\subsubsection{Objective function}

The goal of the paper is the minimizing the power loss, and that can be given as follows:

$$
F_{\text {obj }}=\operatorname{minimize}\left(P_{\text {loss }}\right)=\frac{\sum_{i=1}^{N}\left(P_{\text {Lineloss }}(i)\right)_{a f f e r D G}}{\sum_{i=1}^{N}\left(P_{\text {Lineloss }}(i)\right)_{b f f o r e D G}}
$$

where $N$ is the total number of branches

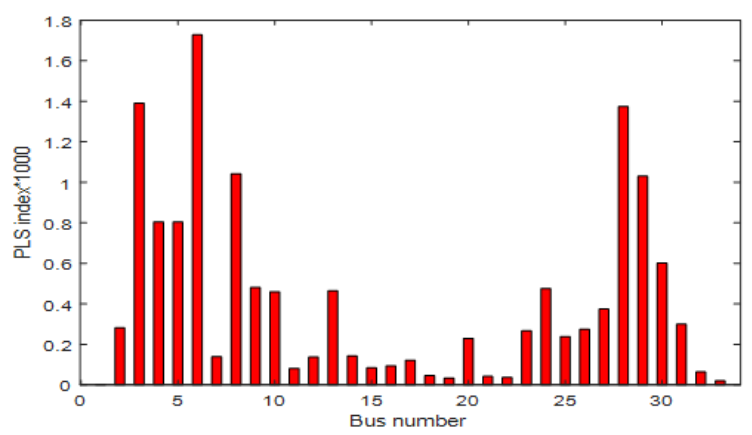

Fig. 2. The calculated PLS index values. 


\subsubsection{Equality constraints}

The power balance constraints of RDS as follows [2]:

$$
\begin{gathered}
P_{\text {substaion }}+\sum_{l 1}^{M} P_{D G}(l)=\sum_{l=1}^{L} P_{\text {Lineloss }}(l)+\sum_{j=1}^{M} P_{d}(j) \\
Q_{\text {substaion }}+\sum_{l 1}^{M_{D G}} Q_{D G}(l)=\sum_{l=1}^{L} Q_{\text {Lineloss }}(l)+\sum_{j=1}^{M} Q_{d}(j)
\end{gathered}
$$

where, $P_{\text {substation }}$ and $Q_{\text {substation }}$ are active and reactive powers of the substation, respectively. $M_{D G}$ is integrated DG unit number, $L$ is branch numbers.

\subsubsection{Inequality constraint}

- Voltage limits

The voltages of overall buses must meet the following limit.

$$
V_{\min } \leq\left|V_{i}\right| \leq V_{\max }
$$

where $V_{\min }$ and $V_{\max }$ are lower and upper voltages of buses.

- Power generation constraints

The generated power by DGs must meet the following constraints [1].

$$
\begin{aligned}
& \sum_{l=1}^{M G} Q_{D G}(l) \leq \frac{3}{4} *\left[\sum_{l=1}^{L} Q_{\text {Lineloss }}(l)+\sum_{j=1}^{M} Q d(j)\right] \\
& P_{D G}^{\min } \leq P_{D G}(l) \leq P_{D G}^{\max } \\
& Q_{D G}^{\min } \leq Q_{D G}(l) \leq Q_{D G}^{\max }
\end{aligned}
$$

where, $P_{D G}^{\max }$ and $P_{D G}^{\min }$ are the upper and lower active power constraints of the DG unit, respectively. $Q_{D G}^{\max }$ and $Q_{D G}^{\min }$ are the upper and lower reactive power constraints of the DG unit, respectively.

- The power factor (PF) constraints of the DG units as follows:

$$
P F_{D G, \min } \leq P F_{D G, i} \leq P F_{D G, \max }
$$

where, $P F_{D G \text {, min }}$ and $P F_{D G \text {, max }}$ are the lower and upper PF constraints of the DG unit, respectively

- The total power limitation of branches

$$
S_{B i} \leq S_{B i(\text { rated })}
$$

where $S_{B i(\text { rated })}$ is the acceptable total power of branch $i$. 


\subsection{Proposed ASO}

ASO has been proposed by W. Zhao et al. [10]. It is a new algorithm of metaheuristic optimization inspired by physics, ASO inspired by basic molecular dynamics. ASO mathematically models and simulates a model of the motion of atoms in nature, where atoms interact with each other through the interaction forces.

The key steps of the proposed ASO are as follows:

Step 1. Generated randomly new population (NP) of atoms X (solutions) and their velocity $\mathrm{V}$, and fit $_{\text {Best }}=$ Inf .

$$
\begin{gathered}
x_{i j}=x_{\min , j}+\left(x_{\max , j}-x_{\min , j}\right) * \text { rand } \\
V_{i j}=V_{\min , j}+\left(V_{\max , j}-V_{\min , j}\right) * \text { rand }
\end{gathered}
$$

where, ${ }^{x_{\min , j}}, V_{\min , j}$ and $x_{\max , j}, V_{\max , j}$ are the minimum and maximum limits of the dimension (D) $\mathrm{j}$.

Step 2. Calculate the fitness values for each atom i.

$$
\operatorname{fit}\left(X_{i}\right)
$$

If $f i t\left(X_{i}\right)<f i t_{\text {Best }}$, then $f i t_{\text {Best }}=f i t\left(X_{i}\right)$ and $X_{\text {Best }}=X_{i}$ end if.

Step 3. Calculate the mass of the atom:

$$
\begin{gathered}
M_{i}(t)=e^{-\frac{f i t_{i}(t)-f i t_{\text {ext }}(t)}{f i i_{\text {worst }}(t)-f i t_{\text {best }}(t)}} \\
m_{i}(t)=\frac{M_{i}(t)}{\sum_{j=1}^{N} M_{j}(t)}
\end{gathered}
$$

where $m_{i}(t)$ is the mass of the $i^{\text {th }}$ atom at the $t^{\text {th }}$ iteration

where ${ }^{f i t_{\text {best }}}(t)$ and ${ }^{f i t_{\text {worst }}(t)}$ are the minimum and the maximum fitness value (FV), and expressed as:

$$
\begin{aligned}
& f i t_{\text {best }}(t)=\min f i t_{i}(t), \quad i \in\{1,2, \ldots N\} \\
& f i t_{\text {worst }}(t)=\max f i t_{i}(t), \quad i \in\{1,2, \ldots N\}
\end{aligned}
$$

$f_{i}(t)$ is the FV of the function of the $\mathrm{i}^{\text {th }}$ atom at the $\mathrm{t}^{\text {th }}$ iteration.

Step 4. Determine its $K$ neighbors.

To improve exploration in the first iteration stage, each atom must interact with as many atoms with better physical FVs as its neighbors $\mathrm{K}$ are defined as:

$$
K(t)=N-(N-2) * \sqrt{\frac{t}{T}}
$$

Where $\mathrm{t}$ and $\mathrm{T}$ are the current and maximum iteration numbers, $N$ is the population of atoms 
Step 5. Calculate the total interaction force $F i$ and the constraint force $G i$ using equations (17) and (25), respectively;

$$
F_{i}^{d}(t)=\sum_{j \in K_{b e s t}} \text { rand }_{j} * F_{i j}^{d}(t)
$$

where rand $_{j}$ is a random number.

The interaction force that ensues from the Lennard-Jones (L-J) potential is the priming power of the atomic movement. The force of interaction acted on the atom $I$ of the atom $\mathrm{j}^{\text {th }}$ in the dimension $\mathrm{d}^{\text {th }}$ at the time $\mathrm{t}$, which can be written as:

$$
F_{i j}^{d}(t)=-\eta(t) *\left[2 *\left(h_{i j}(t)\right)^{13}-\left(h_{i j}(t)\right)^{7}\right]
$$

where $\eta(t)$ is depth function to set the rotation zone or attraction, and can be determined as:

$$
\eta(t)=\alpha^{*}\left(1-\frac{t-1}{T}\right)^{3} * e^{-\frac{20 t}{T}}
$$

where $a$ is the depth weight

The functional behaviors of $F^{\prime}$ with various rates of $\eta$ compatible values of $h$ ranking from 0.9 to 2 are shown in Figure 3.

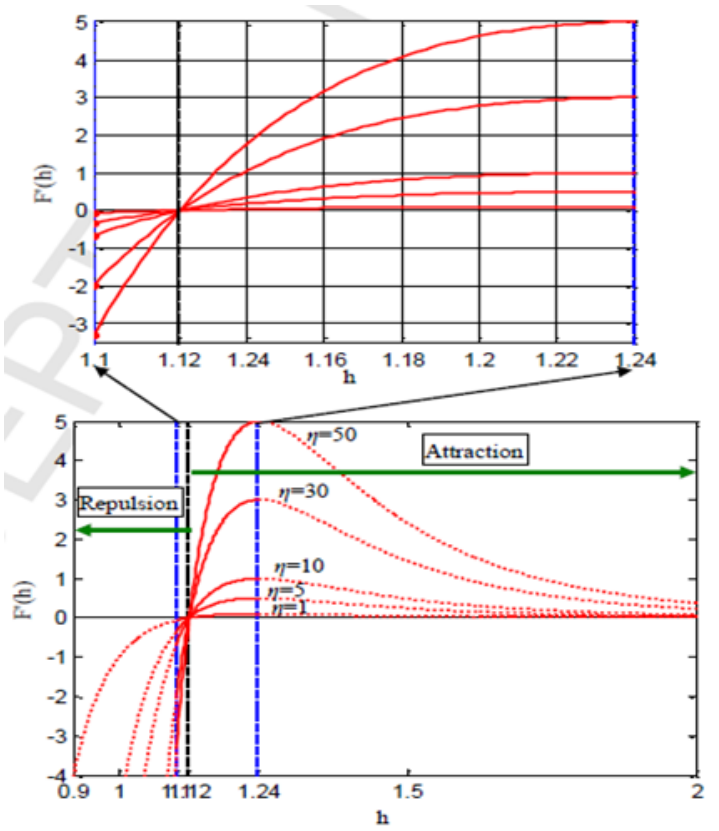

Fig. 3. Functional behaviors of $\mathrm{F}^{\prime}$ with various rates of $\eta$

To enhance exploration, the lower limit value with the lower function rate is set to $\mathrm{h}=$ 1.1 , and the high function value with a higher limit rate is set to $h=1.24$, so it is determined as follows: 


$$
h_{i j}(t)= \begin{cases}h_{\min } & \frac{r_{i j}(t)}{\sigma(t)} \prec h_{\min } \\ \frac{r_{i j}(t)}{\sigma(t)} & h_{\min } \leq \frac{r_{i j}(t)}{\sigma(t)} \leq h_{\max } \\ h_{\max } & \frac{r_{i j}(t)}{\sigma(t)} \prec h_{\max }\end{cases}
$$

where $h_{\min }$ and hmax are respectively, a lower and upper limit of $\mathrm{h}$ and the length scale $\sigma(t)$ is determined as follows:

$$
\sigma(t)=\left\|x_{i j}(t), \frac{\sum_{j \in K_{\text {best }}} x_{i j}(t)}{K(t)}\right\|_{2}
$$

The relative distance of two atoms at $\mathrm{t}$ iteration defined as:

$$
\begin{aligned}
& r_{i j}(t)=\operatorname{norm}\left(x_{i}^{d}(t)-x_{j}^{d}(t)\right) \\
& \left\{\begin{array}{l}
h_{\min }=h_{\min }+g(t) \\
h_{\max }=h_{\max }
\end{array}\right.
\end{aligned}
$$

where, KBest is a subunit of atoms, which is composed of the first atoms of $\mathrm{K}$ with the first 5 atoms with the best FV are considered Kbest. $G$ is the drift coefficient that can cause the technique to move from exploration to exploitation, which is defined as:

$$
\begin{aligned}
& g(t)=0.1 * \sin \left(\frac{\pi}{2} * \frac{t}{T}\right) \\
& G_{i}^{d}(t)=\lambda(t) *\left(x_{\text {best }}^{d}(t)-x_{i}^{d}(t)\right)
\end{aligned}
$$

where $^{\lambda(t)}$ is Lagrange multiplier and defined as:

$$
\lambda(t)=\beta e^{-\frac{20 t}{T}}
$$

where $\mathrm{b}$ is the multiplier weight.

Step 6. Calculate the acceleration using equation (27);

$$
\begin{aligned}
a_{i}^{d}(t) & =\frac{F_{i}^{d}(t)}{m_{i}^{d}(t)}+\frac{G_{i}^{d}(t)}{m_{i}^{d}(t)}=-\alpha *\left(1-\frac{t-1}{T}\right)^{3} * e^{-\frac{20 t}{T}} * \\
& * \sum_{j \in K_{\text {best }}} \frac{\operatorname{rand}_{j} *\left[2 *\left(h_{i j}(t)\right)^{13}-\left(h_{i j}\right)^{7}\right]}{m_{i}(t)} * \\
& * \frac{\left(x_{i}^{d}(t)-x_{j}^{d}(t)\right)}{\left\|x_{i}(t), x_{j}(t)\right\|_{2}}+\beta e^{-\frac{20 t}{T}} * \frac{x_{\text {best }}^{d}(t)-x_{i}^{d}(t)}{m_{i}(t)}
\end{aligned}
$$


Step 7. Update the velocity and the position of atoms

$$
\begin{aligned}
& V_{i}^{d}(t+1)=\operatorname{rand}_{i}^{d} * V_{i}^{d}(t)+a_{i}^{d}(t) \\
& x_{i}^{d}(t+1)=x_{i}^{d}(t)+V_{i}^{d}(t+1)
\end{aligned}
$$

Table 1. Describes the parameters and operational constraints of this study

\begin{tabular}{|c|c|}
\hline \multicolumn{2}{|c|}{ Table 1. Parameters and operational constraints. } \\
\hline Parameter & Value \\
\hline Population of atom & 50 \\
\hline Number of iterations & 200 \\
\hline Depth weight & 50 \\
\hline Multiplier weight & 0.2 \\
\hline Bus system voltage limits & $0.9 p . u . \leq V_{i} \leq 1.05 p . u$. \\
\hline DG's real power generation limit & $\mathbf{O} \boldsymbol{M W} \leq \boldsymbol{P}_{D G, i} \leq 3 \boldsymbol{M W}$ \\
\hline DG's power factor limit & $\mathbf{0 . 7} \leq \boldsymbol{P F _ { D G , i }} \leq 1$ \\
\hline
\end{tabular}

\section{Results and Discussion}

To show the effectiveness of the proposed approach applied to IEEE 33-bus RDS. This RDS with real and reactive power is $3715 \mathrm{~kW}$ and $2300 \mathrm{kVAr}$, respectively. The base power loss of this system is $202.6 \mathrm{~kW}$, and the lower bus voltage is 0.9038 p.u. Other information can be found in [16]. Load flow analysis is performed in the MATLAB ${ }^{\circ}$. The single line scheme of the IEEE 33-bus system is shown in Figure 4.

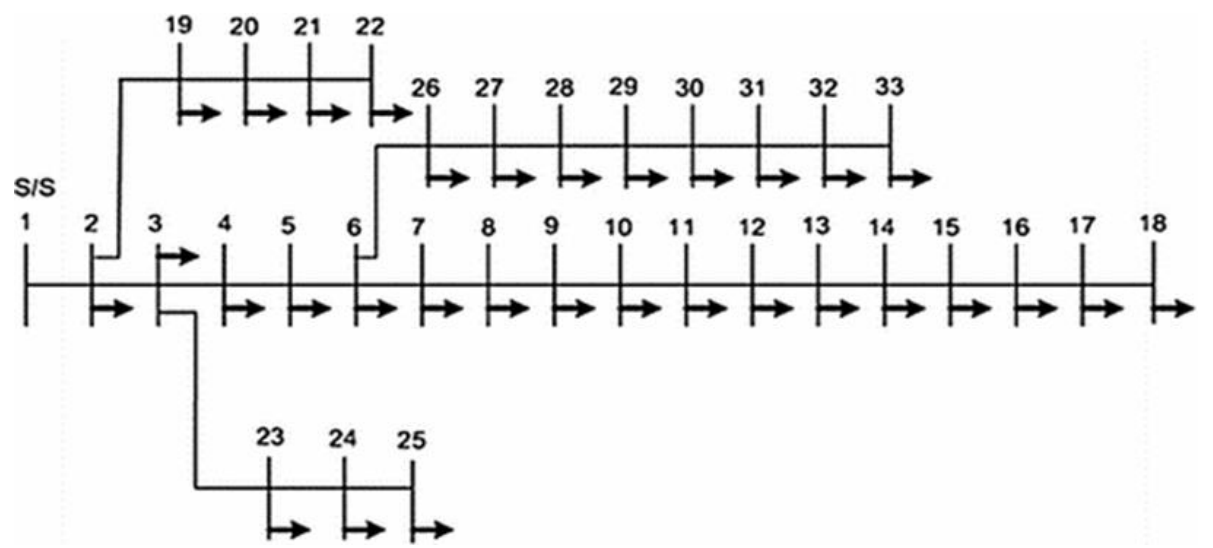

Fig. 4. Single line diagram of IEEE 33-bus system

The system power loss is decreased to $111.027 \mathrm{~kW}, 87.166 \mathrm{~kW}$, and $72.79 \mathrm{~kW}$ by integrating one, two, and three PV units and power loss is decreased to $67.83 \mathrm{~kW}, 28.63$ $\mathrm{kW}$, and $11.74 \mathrm{~kW}$ by integrating one, two, and three WT units in RDS, respectively. Integration of one, two, and three PV units improves the minimum voltage to $0.9424 \mathrm{pu}$, $0.9685 \mathrm{pu}$, and $0.96868 \mathrm{pu}$, and integration of one, two, and three WT units improves the minimum voltage to $0.95835 \mathrm{pu}, 0.98025 \mathrm{pu}$, and $0.99212 \mathrm{pu}$, respectively as shown in 
Figures 5-7. From these figures, it is clear that the voltage profile of each bus has been significantly improved relative to the base case by optimally determining the sizes and locations of the DG units by using the proposed approach. Besides, the proposed approach obtains the minimum power loss compared to other techniques, as shown in Table.2.

Table 2. The results comparison of proposed approach and other techniques

\begin{tabular}{|c|c|c|c|c|c|c|}
\hline \multicolumn{2}{|c|}{$\begin{array}{c}\text { Type and number of } \\
\text { DG units }\end{array}$} & GA [] & BSOA [] & EA [] & Hybrid [] & ASO \\
\hline \multirow[t]{2}{*}{$\begin{array}{l}\text { One } \\
\text { PV }\end{array}$} & $\begin{array}{l}\text { Obtained bus } \\
\text { (Size (kW } \\
\text { /PF)) }\end{array}$ & $\begin{array}{c}8(1857.5 \\
/ 1)\end{array}$ & $\begin{array}{c}6(2380 \\
/ 1)\end{array}$ & $6(2530 / 1)$ & $6(2530 / 1)$ & $6(2590.2 / 1)$ \\
\hline & $\begin{array}{l}\text { Obtained } \\
\text { power loss } \\
(\mathrm{kW})\end{array}$ & 118.12 & 132.64 & 111.42 & 111.07 & 111.027 \\
\hline \multirow[t]{2}{*}{$\begin{array}{l}\text { Two } \\
\text { PV }\end{array}$} & $\begin{array}{l}\text { Obtained bus } \\
\text { (Size }(\mathrm{kW} \\
\text { /PF)) }\end{array}$ & $\begin{array}{c}13(880.11 \\
/ 1) \\
31(924.11 \\
/ 1)\end{array}$ & $\begin{array}{c}6(1718 \\
/ 1) \\
8(840.11 \\
/ 1)\end{array}$ & $\begin{array}{c}13(844 / 1) \\
30(1149 / 1)\end{array}$ & $\begin{array}{c}13(844 / 1) \\
30(1149 / 1)\end{array}$ & $\begin{array}{c}13(851.51 \\
/ 1) \\
30(1157.61 \\
/ 1)\end{array}$ \\
\hline & $\begin{array}{c}\text { Obtained } \\
\text { power }(\mathrm{kW})\end{array}$ & 89.341 & 96.5 & 87.43 & 87.172 & 87.166 \\
\hline \multirow[t]{2}{*}{$\begin{array}{c}\text { Three } \\
\text { PV }\end{array}$} & $\begin{array}{l}\text { Obtained bus } \\
\text { (Size }(\mathrm{kW} \\
\text { /PF)) }\end{array}$ & - & - & $\begin{array}{c}13(798 / 1) \\
30(1050 / 1) \\
24(1099 / 1)\end{array}$ & $\begin{array}{c}13(798 / 1) \\
30(1050 / 1) \\
24(1099 / 1)\end{array}$ & $\begin{array}{c}13(801.71 \\
/ 1) \\
30(1053.61 \\
/ 1) \\
24(1091.31 \\
/ 1) \\
\end{array}$ \\
\hline & $\begin{array}{l}\text { Obtained } \\
\text { power loss } \\
(\mathrm{kW})\end{array}$ & - & - & 72.787 & 72.787 & 72.79 \\
\hline \multirow[t]{2}{*}{$\begin{array}{l}\text { One } \\
\text { WT }\end{array}$} & $\begin{array}{l}\text { Obtained bus } \\
\text { (Size }(\mathrm{kW} \\
\text { /PF)) }\end{array}$ & $\begin{array}{l}8(2265 \\
/ 0.82)\end{array}$ & $\begin{array}{c}6(2980 \\
/ 0.95)\end{array}$ & $\begin{array}{c}6(3028 \\
/ 0.82)\end{array}$ & $\begin{array}{c}6(3119 \\
/ 0.82)\end{array}$ & $\begin{array}{c}6(2558.51 \\
/ 0.82)\end{array}$ \\
\hline & $\begin{array}{c}\text { Obtained } \\
\text { power loss } \\
(\mathrm{kW})\end{array}$ & 82.78 & 72.68 & 67.937 & 67.937 & 67.83 \\
\hline \multirow[t]{2}{*}{$\begin{array}{l}\text { Two } \\
\text { WT }\end{array}$} & $\begin{array}{l}\text { Obtained bus } \\
\text { (Size }(\mathrm{kW} \\
\text { /PF)) }\end{array}$ & $\begin{array}{c}13(777 \\
/ 0.89) \\
29(1032 \\
/ 0.7) \\
\end{array}$ & - & $\begin{array}{c}13(1039 \\
/ 0.91) \\
30(1508 \\
/ 0.72) \\
\end{array}$ & $\begin{array}{c}13(938 \\
/ 0.90) \\
30(1573 \\
/ 0.73) \\
\end{array}$ & $\begin{array}{c}13(858.31 \\
/ 0.91) \\
30(1089.11 \\
/ 0.7) \\
\end{array}$ \\
\hline & $\begin{array}{l}\text { Obtained } \\
\text { power loss } \\
(\mathrm{kW})\end{array}$ & 31.98 & - & 28.98 & 28.98 & 28.63 \\
\hline \multirow[t]{2}{*}{$\begin{array}{l}\text { Three } \\
\text { WT }\end{array}$} & $\begin{array}{l}\text { Obtained bus } \\
\text { (Size }(\mathrm{kW} \\
\text { /PF)) }\end{array}$ & - & - & $\begin{array}{c}13(873 \\
/ 0.9) \\
30(1439 \\
/ 0.71) \\
24(1186 \\
/ 0.89) \\
\end{array}$ & $\begin{array}{c}13(886 \\
/ 0.90) \\
30(1450 \\
/ 0.71) \\
24(1189 \\
/ 0.90) \\
\end{array}$ & $\begin{array}{c}24(1069.91 \\
/ 0.9) \\
30(1029.91 \\
/ 0.71) \\
13(793.81 \\
/ 0.9) \\
\end{array}$ \\
\hline & $\begin{array}{l}\text { Obtained } \\
\text { power loss } \\
(\mathrm{kW})\end{array}$ & - & - & 11.76 & 11.8 & 11.74 \\
\hline
\end{tabular}




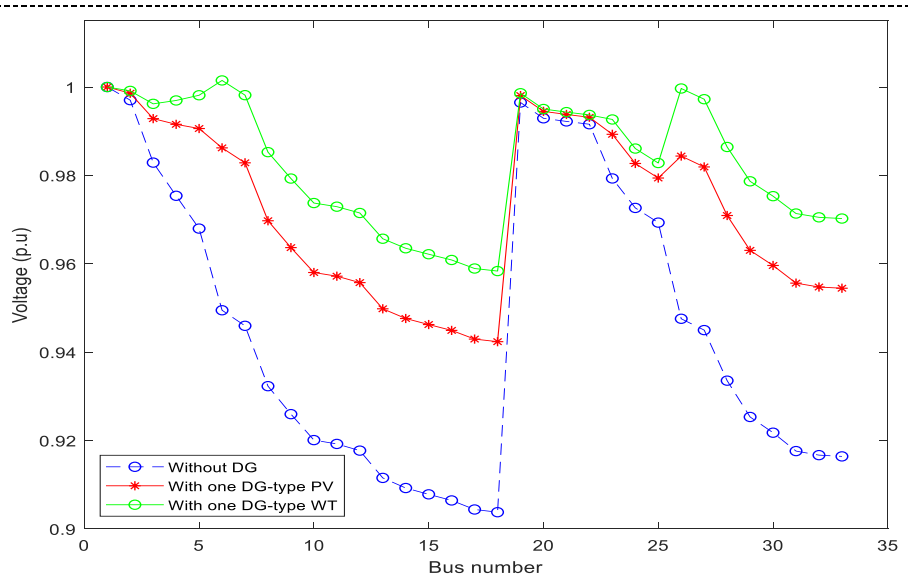

Fig.5. Influence of one DG unit on the voltage profile
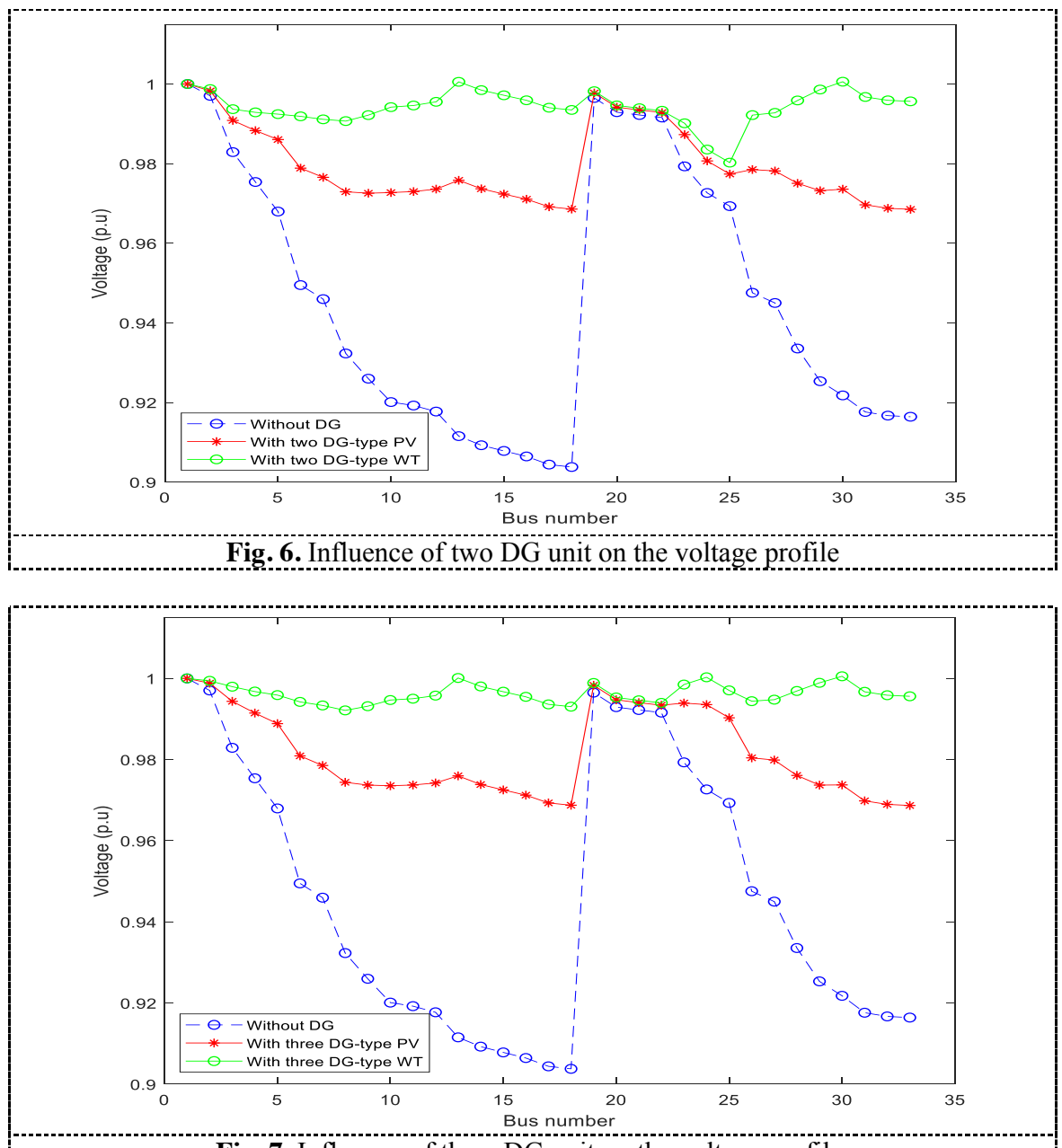

Fig. 7. Influence of three DG unit on the voltage profile. 


\section{Conclusion}

In this paper, an atom search optimization algorithm (ASO) with a power loss sensitivity (PLS) index has been proposed for the solution problem of optimal allocation of DG units in RDS. The main goal of the proposed approach is to minimizing power losses. The proposed approach has been applied to the IEEE 33-bus system and compared results obtained with existing optimization techniques. The proposed approach effectively finds the optimal solution (minimum power loss) compared to other optimizations technique. Future research on the topic may include uncertainty of these sources.

\section{References}

1. Khasanov M, Kamel S., and Hasanien H.M. 2nd International Conference on Smart Power \& Internet Energy Systems (SPIES), p p . 138-143, (2020)

2. Khasanov M, Kamel S, Abdel and Mawgoud H. 21st International Middle East Power Systems Conference (MEPCON),pp..354-359, (2019)

3. Khasanov M, Kamel S, Tostado and Véliz M. IEEE International Conference on Environment and Electrical Engineering pp.1-5, (2020)

4. Khasanov M, Kamel S and Xie K 2019 Combined Tree Growth Algorithm for Optimal Position and Size of Multiple DGs with Different Types in Distribution Systems' 2019 IEEE Innovative Smart Grid Technologies - Asia (ISGT Asia) pp $1265-1270$

5. Hassan A.A., Fahmy F.H., Nafeh A., and Abu-Elmagd M A J I J O S E (2017)

6. Kamel S, Awad A and H Turkish Journal of Electrical Engineering and Computer Sciences, (2019)

7. El-Fergany A. International Journal of Electrical Power \& Energy Systems 64, pp.1197- 1205, (2015)

8. Mahmoud K., Yorino N., and Ahmed A. IEEE Transactions on Power Systems 31, pp. 960-969, (2016)

9. Kansal S, Kumar V and Tyagi B. International Journal of Electrical Power \& Energy Systems 75, pp226-235 (2016)

10. Zhao W, Wang L and Zhang Z 2019 Future Generation Computer Systems $91601-$ 610

11. Selvan M., and Swarup K.S. International Conference on Power System Technology 2, pp.1168-1173, (2004)

12. Chang G W, Chu S Y., and Wang H L 2007 An Improved Backward, Forward Sweep Load Flow Algorithm for Radial Distribution Systems, (2007)

13. Zhang P. Boundary analysis of distribution reliability and economic assessment vol. 25, no. 2, pp. 714-721, (2009)

14. Khasanov M, Kamel S, Xie K, Zhou P and Li B. Allocation of Distributed Generation in Radial Distribution Networks Using an Efficient Hybrid Optimization Algorithm, IEEE Innovative Smart Grid Technologies - Asia (ISGT Asia) pp. 1300-1305, (2019)

15. Abdel-Mawgoud H, Kamel S, Khasanov M., and Khurshaid T. A strategy for PV and BESS allocation considering uncertainty based on a modified Henry gas solubility optimizer, (2021)

16. Baran M E., and Wu F.F. IEEE Transactions on Power Delivery 4 1401-1407, (1989) 